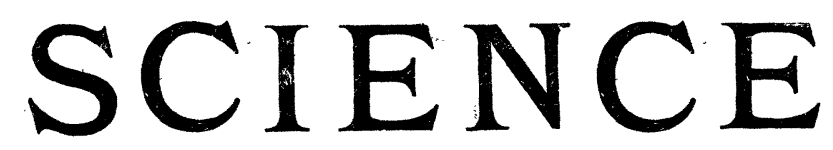

A WEEKLY JOURNAL DEVOTED TO THE ADVANCEMENT OF SCIENCE, PUBLISHING THE OFFICIAL NOTICES AND PROCEEDINGS OF THE AMERICAN ASSOCIATION FOR THE ADVANCEMENT OF SCIENCE.

Editorial Commitrie : S. Newcomb, Mathematics; R. S. Woodward, Mechanios; E. C. Pickering Astronomy ; T. C. Mendenhall, Physios ; R. H. Thurston, Engineering ; Ira Remsen, Chemistry ;

Charlems D. Walcott, Geology ; W. M. Dafis, Physiography ; Henry F. Osborn, Paleon-

tology ; W. K. Brooks, C. Hart Mrrriam, Zoology ; S. H. Scudder, Entomology ; C. E.

Bessey, N. L. Britton, Botany ; C. S. Minot, Embryology, Histology ; H. P.

Bowditch, Physiology; William H. Whlch, Pathology ;

J. McKeren Catteli, Psyohology.

Friday, August 14, 1903.

CONTENTS:

Ten Years of American Psychology: Professor Edward Franklin Buchner...... 193

Professor Alexander Graham Bell on Kite Construction: H. H. Clayton.......... 204

Scientific Books:-

Livingston on the Rôle of Diffusion and Osmotic Pressure in Plants: Professor

Charles E. Bessey................ 208

Scientific Journals and. Articles.......... 209

Societies and Academies:-

The Biological Society of St. Louis: W. L. EukenBerry ................... 210

Discussion and Correspondence:-

The Advantages of the Government Cinchona Plantation in Jamaica as a Tropical Botanical station: Professor Duncan S. JoHN-

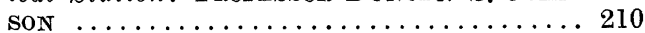

Shorter Articles:-

The Stratigraphic Position of the Judith River Keds and their Correlation with the Belly River Beds: J. B. HATchen, T. W. Stanton. Notes on the Geology of Long Island: A. C. Veatch. The Kent County, Mich., Upland Plant Societies: Dr. Francis

DANIELs. Discovery of the Breeding Area

of Kirtland's Warbler in Michigan: DR. C.

O. Adams...................... 211

Current Notes on Meteorology:-

Jlimate of Cairo; Thunderstorms and the Moan; Rain and Dust Fall in Edinburgh in

1002: Professor R. DeC. Ward......... 217

New York Zoological Park: H. F. O....... 218

The Lister Institute............... 219

Scientific Notes and News............ 220

University and Educational News........ 224

MSS. intended for publication and books, etc., intendefor review should be sent to the responsible editor, Professor J. McKe?n Cattell, Garrison-on-Hudson, N. Y.

\section{TEN YEARS OF AMERICAN PSYCHOLOGY: 1892-1902.*}

I.

Some future historian of our science will have a very interesting opportunity to trace and to describe the characterizing features of the so-called 'modern' psychology, and the alleged discoveries made by its devotees. The name of this science and its titular employment in the writing of books are a little bit younger than the discovery of America. It is, perhaps, both too early and too venturesome to suggest that there might be some mystic connection between that name and that historic event. The habilitation of the lore incorporated under that name as a 'science' began just half a century ago. Lotze's 'Medicinische Psychologie' appeared in 1852, and that year must be regarded as the beginning of the new psychological calendar. Some twenty years later Wundt's 'Grundzüge der Physiologische Psychologie' appeared (1874), and about a quarter of a century passed before the first distinct experimental institute for the psychologist had its beginning at Leipzig (1878). After thirty years America had its first laboratory

* A paper prepared for the Eleventh Annual Meeting of the American Psychological Association, December 30, 1902 to January 1, 1903, at Washington, D. C. 
(1883). The end of the fourth decennium permits us to see the organization of our association. And the close of the fifth finds us here and now-in full psychological array, shall we say? To the chronicler, at least, the decennia accentuate themselves by reason of the paramount importance of the events which have brought us together.

Our hoped-for historian will probably find himself in a position to point out the importance of these fifty years as residing in their revolutionary results in defining the conception and the method of psychology. Prior to this era, psychology was well regarded as a waif; it was not received by the students of facts, and it was gingerly given a berth by the great chasers after world categories. The revolution which has given us a 'scientific' psychology, the historian will have to say, proceeded in two directions. First, it developed a general type of method, which wrought the great change from a speculative defense of the application of certain theoretical interpretations of every variety of inner experience, to a factual, inductive, measurable, experimental mode of approach to that same experience. The central significance of this change is amply seen in the contrast presented by the fact that modern psychology finds its object is constant with that inner experience-the soul of man remaining the same, so we may assume-but the conclusions of the study of it-how different from the conclusions of any era which has preceded! No less has its influence been exerted in the direction of creating essentially new problems concerning the behavior of mind. Second, it has introduced a basal conception which has shifted from the individualistic, or substantial view of the system builder, to that of the functional, phenomenal view of cosmic evolution, irrespective of the particular formulation given to that idea. In- stead of continuing to regard mind as a point of persistent regard with the old psychology, the 'new' has demanded that the 'process' interpretation shall alone be considered fruitful. The revolution in psychological method arose and flourished in Germany; that in conception is the contribution largely of English thinking, which took its definite shape about 1855 . The flowering of the former has given us 'experimental' psychology; of the latter, 'genetic' psychology. Such, it seems to me, must be looked upon as the polarization of the psychological thinking which it is given to us to perpetuate or radically to modify.

It may seem to be a piece of venturesome youthfulness and daring jingoism to speak of 'American' psychology, and to define for a science precise boundaries both in space and in time. That this is but a superficial impression is to be seen readily from our desire to emphasize the domestication of the term 'psychology' within our national borders, which has practicallynot essentially-occurred within the time limit of the decennium just ended. In the past, American psychology sailed under the terms of 'mental and moral philosophy,' which have even now some fixed and secure anchorages. It, too, was molded chiefly by the theologians, whose line of intellectual descent runs back almost without break to Scottish realism. The good thing in this step-motherly care over psychology consisted in the wholesome fact that that form of speculation attributec a rather definable degree of primacy and reality to human consciousness, which are so fundamental to the genuine psychological attitude. And that was about the only good thing in this theological fostering. That one may venture to speak of an 'American' psychology is to be regarded as a recognition of an undoubted 
effort on this side of the Atlantic to renounce our former mode of intellectual dependence upon some foreign system, or upon some old-world thinker. At the same time, no one can be more ready than ourselves loudly to decry jingoism in science. For science, happily, knows no nationality. It is the common heritage, in sharing which no form of social prejudice can despoil us. It is fully possible, however, for the development of a science within a national border to give a definite contribution to the type of life therein growing,- and especially is this a hopeful probability the nearer the science approaches the needs of a complete science of man.

The chief justification for our speaking of American psychology is to be found in the fact that our association is just ten years old, and resides in the desire to contribute modestly to the celebration of the decennium by passing in review the work of the association and its influences upon the situation of psychology presented in the United States. Accept the name of our organization, and the adjective in our theme follows as an appropriate sequence. Moreover, it ought to be a good tonic to insist on the value of psychology accruing through the use of the adjective marking nationality.

Inasmuch as the appearance of the American Psychological Association was not a Minerva-like birth, it is proper that a glance should be given to the stock in trade possessed by psychology ten years ago. The state of the science during the decennium preceding the one under review was very satisfactory and encouraging. The gradual influx of its European developments into American thinking took form in a number of definite achievements, which rapidly multiplied in the years to follow. The perfection of exact methods, the adaptation of instruments to test reactions of the simpler order, and the close correlation between the data of cerebral physiology and well-established groups of mental phenomena, tended at first to bring psychological advances into disrepute among those outside its own domain who might have a care for its fortunes, and to gain for these results, in the mouths of theologians and other convenient idealists, the opprobrious epithet of 'materialistic.' The helpfulness of man's self-study for his own development was dangerously negleeted in these criticisms, and even the pittance of a culture value to the pursuit of this subject was barely allowed to its chief defenders.

Nevertheless, the decade brought forth noteworthy achievements, both in American scholarship and in American educational institutions. The first American attempt at exact psychological demonstration probably occurred at Harvard in our centennial year. The first laboratory for psychology in America was opened in 1883 by President G. Stanley Hall, as professor of psychology and pedagogy in the Johns Hopkins University. The same year witnessed sporadic efforts here and there to study and to teach something of physiological psychology. The waning of the old and the dawning of the new modes of psychologizing were interestingly marked in three books which appeared in 1886 and 1887: McCosh's 'Psychology: The Cognitive Powers,' Bowne's 'Introduction to Psychological Theory' and Dewey's 'Psychology.' The first tried in a well-intentioned way, at least, to realize the shifting of the center of psychology; the second fought the one-sided materialistic issues of forty years earlier; and the third seriously welded the newer facts of science into the system of absolutism and made psychology a museum of well-balanced definitions. These 
imperfect or combative tendencies practically came to their American end in the year 1887, when the American Journal of Psychology was founded by President Hall, and Professor George Trumbull Ladd published his 'Elements of Physiological Psychology.' This was the first book to present a careful, synthetic statement of psycho-physical facts in the English language. Through the double reason of their priority in time and their scientific saneness, these two foundations have had the most influence upon the tenor of later American psychology: the one by its emphasis upon research, the other for the academic presentation of the new subject and interpretations of the higher manifestations of mind. For the virtues of a science are largely to be sought in the two directions of original investigation and adequate teaching. The following year, 1888, witnessed the establishment of the first American chair for psychology alone with a laboratory at the University of Pennsylvania, with Professor J. McKeen, Cattell in the chair. Here, also, I believe, was given the first instruction in experimental psychology to undergraduate students. Our stock in trade was increased in the two years following by the appearance of Professor J. Mark Baldwin's 'Handbook of Psychology' (first part, 1889), and Professor William James's long-awaited 'The Principles of Psychology' (1890). Here at last came a mighty reinforcement to the psychological impetus, which had been dealing so long in 'first things,' and whose momentum was growing so rapidly; and here came also that added rich flavor which has placed American psychology upon the high pedestal of literary expression, and made it most palatable to the popular mind, while being descriptively in close accord with the facts.
In 1891, our esteemed president began the publication of his splendidly organized and selected work, 'A Laboratory Course in Physiological Psychology.' This second great American step in the adoption of a pedagogical method was sure to be taken, and thus early did a pioneer selective teacher enable the transformed science to take its accredited position among university studies.

In these varied ways of laboratories, chairs and systematic literature, American psychology took on a splendid and resistless form of organization in the universities and colleges, whence radiated the multiple specialties which were developed by those who followed the leadership of these agencies in our higher education. An additional item taken from a more popular gauge of psychological values offers a fitting opportunity to make the contrasts between the psychology that had been and the psychology that was soon to be. The National Educational Association of the United States, at its Toronto meeting in 1891, gave a pinch of attention to experimental psychology. Two round tables, presided over by President Hall, were permitted, but not recognized as a part of the work of the association. The American policy of indebting itself to the old World continued during these years in the usual double fashion of sending our students abroad for psychological specialization and by bringing in translations of foreign literature. This double mode of our enrichment has placed a blanket mortgage, I fear, upon the stability of the confidence of the American academic administrators in the resources of our own institutions. Certain additional features in the situation ten years ago may be reserved for more fitting mention later. 
TEN YEARS INSIDE THE ASSOCIATION.

The increasing objectivity of psychology in America was augmented by the organization of our association in 1892. When the American Journal of Psychology moved to the 'Heart of the Commonwealth' of Massachusetts, its editor found himself near the center of things psychological, at least in New England. In the hope of conserving the great gains which had been made for the science, and with the desire of having an exchange where psychological efforts might be pooled and where a more personal and direct mode of checking off results might be available than through the existing channels of publication, President Hall nursed the idea of a society of psychologists, and took counsel by pen and by mouth with many workers in this field. Everybody consulted was in sympathy with the idea, and wanted to become a member of whatever organization might be effected, pledging his hearty cooperation. Fortified and clarified by these preliminaries, including a conference of some length with Professor Ladd, he issued a letter of invitation to more than a score of psychologists to meet at Clark University, on July 8, 1892. A company of men gathered at the appointed time and place, and the preliminary meeting was held, six papers being presented and discussed, and plans projected for a permanent organization. The first annual meeting was held on the 27th and 28th of the December following, at the University of Pennsylvania. Annual meetings have been held in the meantime. The following table presents a summary statement of the features of these meetings, detailing for purposes of ready comparison the items of place, president, election to membership, total membership, attendance of members at each meeting, papers, reports and discussions presented, the number of contributing members and readers not members, research grants, and the treasury balances:*

It is interesting to note that most of the organizing psychologists were interested in the project for the sake of fellowship, friendship and the enjoyment of personality. In reviewing the history of the association, and in attempting to ascertain just what it may have done for its object of advancing the science, we can not simply regard it as a social club, meeting for jolly good times. On the contrary, we must look to the work it has actually accomplished or stimulated and recognized. The annual notice of its meetings sent to its members calls for the title of papers to be read. And to this type of activity our attention must primarily be directed.

I therefore adopted the plan of classifying topically the varied material which has been brought in and given a place at the several meetings, in the form of papers, set discussions and research reports, in order to gather up, in a summary fashion, the actual cooperative achievements within the association. The value of such a summary doubtless depends upon the comprehensiveness of the rubrics selected as representing

* The data are compiled from the reports of the meetings to be found as follows:

'Proceedings of the American Psychological Association.' Macmillan and Co., New York (no date), pp. 29. (Contains accounts of the Preliminary, the First Annual, 1892, and the Second Annual, 1893, meetings.) Third Annual meeting, 1894, in Psychological Review, II., 1895, pp. 149-172. Fourth Annual meeting, 1895, in Psychological Review, III., 1896, pp. 121-133. Fifth Annual meeting, 1896, in Psychological Review, IV., 1897, pp. 107-141. Sixth Annual meeting, 1897, in Psychological Review, V., 1898, pp. 145-171. Seventh Annual meeting, 1898, in Psychological Review, VI., 1899, pp. 146-179. Eighth Annual meeting, 1899, in Psychological Review, VII., 1900, pp. 125-158. Ninth Annual meeting, 1900, in Psychological Review, VIII., 1901, pp. 158-186. Tenth Annual meeting, 1901, in Psychological Review, IX., 1902, pp. 134-155. 
the psychological field. Each psychologist probably has his own pet or changing scheme for dividing the great typical departments of the science as they may appeal to him. I have sought to avoid, in the first instance, such a limitation by following the revised rubrics of 'The Psychological Index,' introduced in 1900, which may be regarded as the latest and perhaps the best existing scheme of division covering that part of the field of psychology which reaches the stage of print. It groups psychological literature under ten chief heads, which are so divided and subdivided as to provide a list of eighty-eight different topics. The following classifica- statistical unit employed in gathering the summary. Such a mode of classification must be based on the equivocal unit derived by making each paper, report or address in a set discussion stand as an integer, becoming the unitary equivalent of every other paper, report or discussion. The amount of psychological material, the expenditure of labor required in its preparation, and the comparative and the net values of its results, either as research or as criticism, represented in this arbitrary unit are completely lost sight of in such a scheme. This is unavoidable. What the table truly represents is the number of times the given psychological topics have

Table I. General Summary of the Meetings of the American Psychological Association.

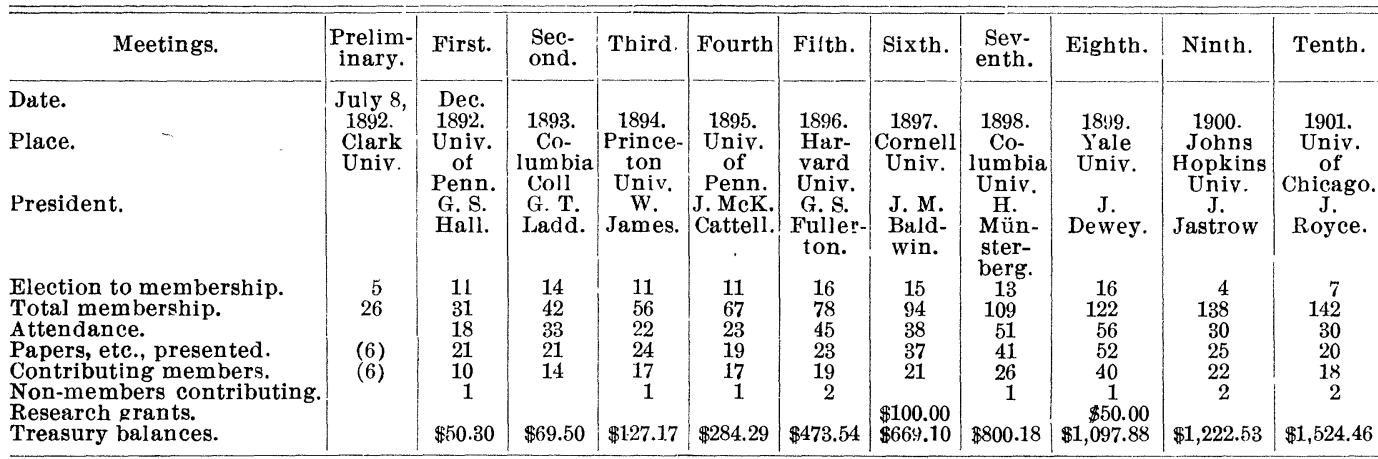

tion of the material available is therefore based on those rubrics. The table includes the presidential addresses and papers presented by title only, but omits the material presented by six persons at the preliminary meeting in 1892 and the general discussions which may have followed any papers.

In preparing such a classification of an enormously varied material, it must be readily confessed that extreme difficulty was often met in deciding the topical properties of a given communication or report. In making the statistical distribution, I have had a special care to represent the themes as faithfully as possible. Special comment must also be made concerning the been more or less within the focus of the association's attention, and the distribution of these topies throughout the whole field of psychological investigation.

Accepting this mode of bunching the work of the ten years, our table offers the following summary. The annual meetings have called forth fifty-six papers on general topics, seven on the nervous system, fifty-three on sensation, thirteen on the characters of consciousness, thirty-four on cognition, two on affection (pleasure and pain being grouped under sensation), seventeen on conation and movement, thirtynine on the higher manifestations of mind, ten on sleep, trance and pathology, forty- 
Table 1I. Classification of Communications Received by the American Psychological Association, 1892-1902.

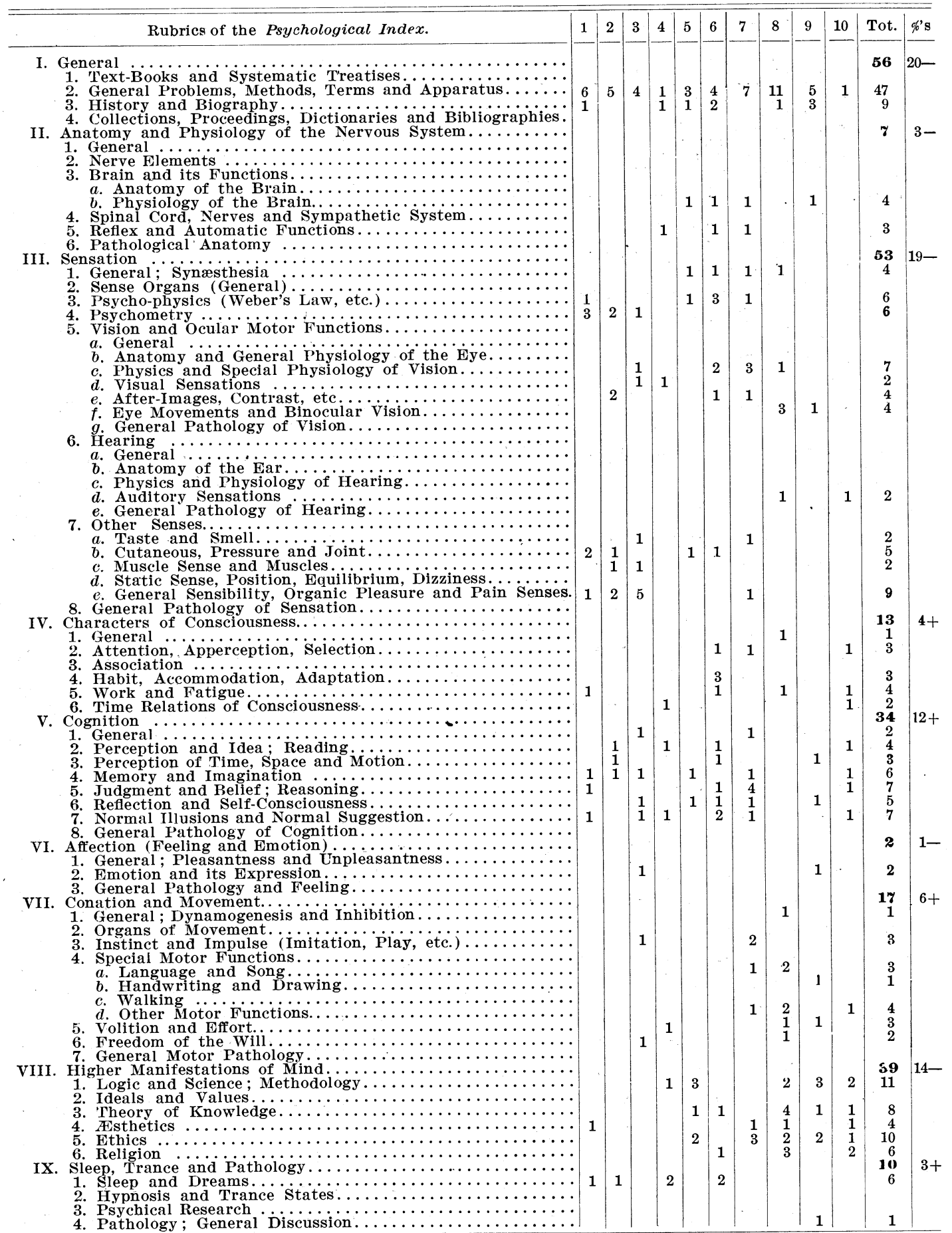


Table II. Classification of Communications Received by the American Psychological Association, 1892-1902.-Continued.

\begin{tabular}{|c|c|c|c|c|c|c|c|c|c|c|c|c|}
\hline Rubrics of the Psychological Index. & 1 & 2 & 3 & 4 & 5 & 6 & 7 & 8 & 9 & 10 & Tot. & \%'s \\
\hline 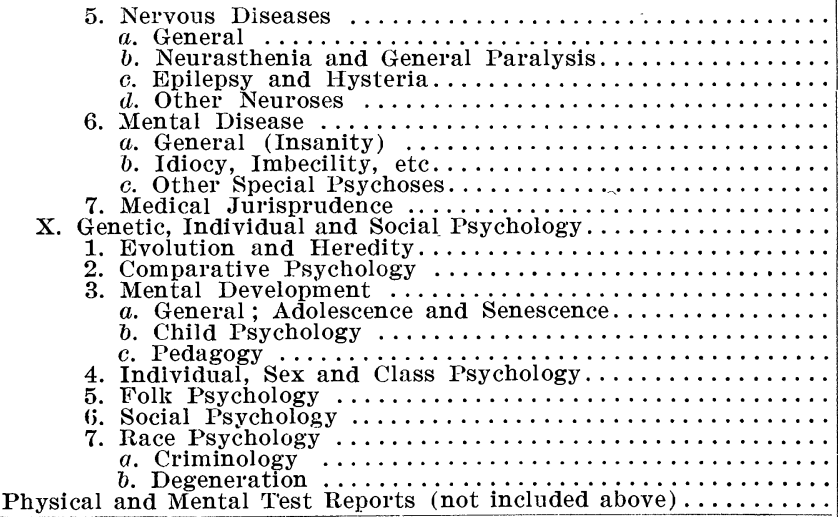 & 1 & 1 & 1 & $\begin{array}{l}1 \\
6\end{array}$ & $\begin{array}{l}1 \\
1\end{array}$ & 1 & $\begin{array}{l}1 \\
1\end{array}$ & $\begin{array}{l}2 \\
5 \\
5\end{array}$ & 2 & $\begin{array}{l}1 \\
1\end{array}$ & $\begin{array}{r}2 \\
\mathbf{4 1} \\
4 \\
7 \\
7 \\
4 \\
7 \\
11 \\
\\
1\end{array}$ & $14+$ \\
\hline Totals ............ & 21 & 21 & 24 & 19 & 23 & 37 & 41 & 52 & 25 & 20 & 283 & 100 \\
\hline
\end{tabular}

one on genetic, individual and social psychology and eleven reports on physical and mental tests, making an aggregate of two hundred and eighty-three communications the association has received. Thirty-eight of the eighty-eight topics listed by 'The Psychological Index' have remained barren throughout the ten years, not having received a single notice. They comprise almost one half of the whole field so listed, showing a rather surprising lack of breadth of treatment. It should be observed, however, that these topics are largely pathological in scope. It is unnecessary here to recount these special topics, which are readily traced in the table.

If one wishes to ascertain the points emphasized in the work of the association thus represented, and learn what have been the lines of dominant interest expressing themselves, he may take numbers as indicative thereof. Arranged in the order beginning with the maximum and ending with the minimum, the summary shows the following results, of course presupposing that all the material has been of a distinctly psychological character: General (56), sensation (53), genetic, social and individual psychology (41), higher manifestation of mind (39), cognition (34), conation and movement (17), characters of consciousness (13), mental tests (11), sleep, trance and pathology (10), anatomy and physiology of the nervous system (7), affection (2).

This topical arrangement offers only the advantages of a cross-section view of the ten years, and is, therefore, inadequate to point out the more interesting perspective of the drifts and tendencies which may be taken to mark the ups and downs of interest in so far as they may have been evoked by the association. I have, therefore, redistributed the material under such rubrics as, it seems to me, more adequately point out the methods, types of interest, and perhaps results, which are what we chiefly seek in the historical way. The selection of the headings employed in Table III., such as 'historical,' 'theoretical,' 'descriptive,' 'experimental,' etc., must be left to justify itself. It need scarcely be added that in the preparation of this table, as was the case in the preceding table, recurring difficulty was encountered in tabbing off a paper under this topic, or under. 
that; but the sanity of the distribution may safely be left to him who is ready to wade through the material for himself. The possible modification of the results thus obtained through the qualities of our arbitrary unit must also not be overlooked. edly philosophical. The last two meetings indicate a noticeable diminution of interest and activity in all these directions, except possibly that of the philosophical group. Only two meetings, the seventh and the eighth, have brought forth something. in

TABle III.

\begin{tabular}{|c|c|c|c|c|c|c|c|c|c|c|c|c|c|}
\hline Type of Communication. & 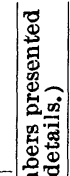 & $\begin{array}{l}\text { 离 } \\
\text { 窟 }\end{array}$ & 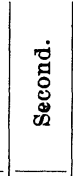 & 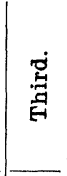 & 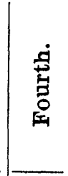 & 蛋 & $\begin{array}{l}\text { 营 } \\
\frac{1}{62}\end{array}$ & 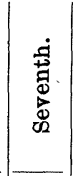 & 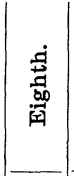 & 竞 & 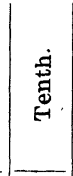 & 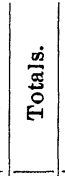 & 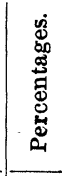 \\
\hline 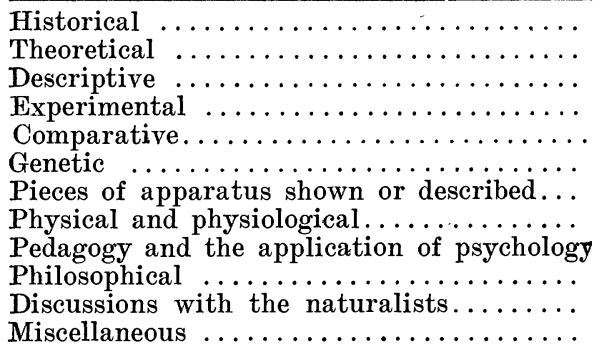 & 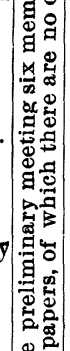 & $\begin{array}{l}1 \\
5 \\
1 \\
1\end{array}$ & $\begin{array}{l}4 \\
2 \\
9 \\
2 \\
2 \\
1\end{array}$ & $\begin{array}{l}6 \\
1 \\
8 \\
1 \\
2 \\
3 \\
2 \\
1 \\
\\
\end{array}$ & $\begin{array}{l}1 \\
2 \\
1 \\
6 \\
1 \\
6 \\
1 \\
1\end{array}$ & $\begin{array}{l}2 \\
1 \\
5 \\
1 \\
1 \\
1 \\
1 \\
2 \\
8 \\
1\end{array}$ & $\begin{array}{r}2 \\
2 \\
2 \\
17 \\
1 \\
3 \\
4 \\
2 \\
2 \\
1 \\
1\end{array}$ & \begin{tabular}{|r|r}
1 \\
1 \\
9 \\
11 \\
1 \\
4 \\
6 \\
3 \\
1 \\
2 \\
1 \\
1 \\
1
\end{tabular} & $\begin{array}{r}3 \\
6 \\
4 \\
10 \\
1 \\
5 \\
7 \\
1 \\
5 \\
8 \\
1 \\
1\end{array}$ & $\begin{array}{l}3 \\
1 \\
1 \\
1 \\
4 \\
1 \\
1 \\
4 \\
2 \\
2 \\
7\end{array}$ & $\begin{array}{l}1 \\
1 \\
2 \\
2 \\
4 \\
1 \\
3 \\
1 \\
1 \\
1 \\
5\end{array}$ & $\begin{array}{r}12 \\
25 \\
23 \\
86 \\
7 \\
25 \\
28 \\
20 \\
12 \\
34 \\
4 \\
7\end{array}$ & $\begin{array}{l}4+ \\
9- \\
8+ \\
30+ \\
3- \\
9- \\
10- \\
7+ \\
4+ \\
12+ \\
1+ \\
3-\end{array}$ \\
\hline Totals & & 21 & 21 & 24 & 19 & 23 & 37 & 41 & 52 & 25 & 20 & 283 & \\
\hline Percentages & 运 & $7+1$ & $7+$ & $8+$ & $7-$ & & & $-15-$ & $18+$ & $9-$ & $7+$ & & 100 \\
\hline
\end{tabular}

* Five papers were offered, but not read, nor mentioned by title.

Resorting again to a statistical indication of the type of psychologizing developed under the sponsorship of the association, we find this summary presenting the following scale of interests. In ten years the association has countenanced eighty-six items of an experimental character, thirtyfour philosophical, twenty-eight on apparatus, twenty-five theoretical, twenty-five genetic, twenty-three descriptive, twenty physical and physiological, twelve historical, twelve pedagogical, seven comparative, seven miscellaneous and four discussions outside. A detailed study of this table shows some interesting contrasts, which the reader can not fail to detect. Attention may be called to some of them. The first, sixth, second, third, seventh and eighth meetings have been predominantly experimental in the order named. The fifth and ninth meetings have been mark- every direction. The pedagogical interests of the science have had the smallest distribution, having been in evidence at only six meetings. In spite of the apparently shifting interests, the association may claim for itself a scientific and inductive character. Forty per cent. of the material belongs to the experimental and apparatus items alone. And more than eleven per cent. properly contributes to the developmental point of view.

Not to undertake a discussion of the contributive values of the papers to the growth of the science is a restriction we have placed upon this historical survey, and the relative merits of the contributions made under each heading we refrain from discussing, except the one instance of the presidential addresses, to which we now turn. 
THE PRESIDENTIAL ADDRESSES.

The ten presidential addresses delivered before the association, which have been included as so many units in the general summaries above, are interesting enough for separate note. These reviews and discussions of our psychological nestors may well be regarded-at least be expected to be so-as indicating the high-water mark reached by the psychological tides in the ebb and flow of the years. They are, in truth, made up of congratulations, instructions and warnings to psychology. There have been ten of them; hence their mere numerical evaluation can count for but little. Four men, Presidents Hall, Ladd, Cattell and Jastrow, have reviewed the history, progress, present position and the prospects of psychology; while six, Presidents James, Fullerton, Baldwin, Münsterberg, Dewey and Royce, have specialized in the problems they presented. Four of the latter, oddly enough, have allowed their presidential thoughts to center around certain cognitive problems of the intellect. One address was expressly devoted to the ontological differentiations between 'Psychology and History.' And, finally, only one address of the ten attempted in extenso to make good the claim that psychology has manifest and manifold practical applications, which occurred under terms of 'Psychology and Social Practice,' the special form of social practice considered being education.

It is not a little interesting to see how hard it is for the psychologists von Fach to keep from trespassing on the green fields of epistemology and metaphysics. The borderland between the scientific and the speculative interests has not only been wandered over, but there have been technical discussions of the latter. This appears unquestionab!r in such themes as 'The Knowing of Things Together,' 'The
Self in its Function of Knower,' 'Recent Logical Inquiries and their Psychological Bearings.' Six presidents dwelt upon the relation between psychology and philosophy, some at length, but all approvingly, including one who has stood most stoutly and clearly for the development of exact, quantitative results in the laboratory. Thus the majority have either affirmed in general or illustratively detailed the interdependent relation between this new science and the old love of reason.

It is disappointing to discover in the scope of these addresses that only three presidents have dealt with the laboratory field of problems, the scope and the conditions of the psychological experiment and the relations of statistical and experimental studies of mind to the total science of psychology. Not even the experimentalist presidents-professionally such, of whom there have been at least three, and at most six-have improved the presidential occasion for giving greater momentum and needed clarity to the experimental development of the science. Where prejudice against the method might have been supposed to exist there has been the greater generosity in recognizing it; and where passion for the method should have existed, there has been actual default in the use made of the opportunity.

One half of the presidents have treated of purely formal, theoretical or speculative interests. Two have supported the genetic method and attempted to vindicate the bearing of the conception of evolution on the problems, methods and attitudes of psychology. Only one has suggested the psychological values of abnormal and decadent experience, while none has dealt with the feelings.

Six presidents have been content to look backwards, or to feel certain only up to the present; while not more than four have looked forward and suggested new prob- 
lems or, other constructive work which would tend to strengthen the science among the sciences and in the esteem of those who mold our, educational and national life. The practical aspects of our science, its values in the conduct of life and its direct bearings in education, medicine, treatment of the unfortunates and in social reforms, its influence upon the development of other sciences, such as biology, anthropology, sociology, logic and ethics, and its aid in the pursuit of art, history and literature, have been clearly affirmed by five presidents, denied by one, and practically ignored by the rest. Only one, I believe, has seriously touched the question of the teaching of psychology to our student body. Which type of a president derived by compositing all these contrasts is the more desirable and the more useful in our leadership in view of the present needs of psychology, is a query that must be referred to each one by himself. .

\section{THE MEMBERSHIP.}

The structure of an association organized in the interest of the advancement of science finds its efficiency not so much in the cortical officials who annually declare their views, as in the interest and efforts of its members, who actively explore the psychological field, offer intelligent criticism of past returns, and otherwise increase its content of fact and in general advance its repute. The scientific and professional aims of the association have been safeguarded within itself, at least, by that modern form of predestination which makes the psychologist's 'calling and election sure.' We have already given an impersonal summary of the work yielded by the elect. We have yet to consider its distribution among the individuals. The fourth, fifth, sixth, seventh and eighth headings in Table I. present the aggregate facts to be considered in detail.
Beginning with twenty-six original members, the association has grown annually, having admitted in the ten years one hundred and forty men and eight women to membership. One man has been elected twice to membership, and seven of the women abide with us still. The present roll includes one hundred and twenty-seven names, showing a total loss, by death and voluntary cessation, of twenty-one members during the ten years. In the matter of attendance, the showing is not as satisfactory as one would wish for the efficiency of the association. The average attendance of members at each meeting has been nearly thirty-five, which is but slightly above the membership at the first annual meeting. Reasons geographical and financial, not to mention others more temporary or personal, must not be over̉looked in interpreting for psychology's fellowship, the percentage the attendance at each meeting has been of the total elections indicated above. It is, however, in place to ask, why has the association apparently lost its hold upon our psychological nestors, who have seemed ready to give place to the younger men? This may indicate a lack of interest on their part in the scientific details that legitimately find place in the proceedings, or it may betoken a change in the community of interest in the unified development of inquiry and criticism. Psychologists above all others are least apt to misinterpret the significance of mere numbers, popularity or enthusiasm. But those who wield greater influence in shaping the association's affairs can well take into consideration the causes of the lessening grip upon many of the more mature and industrious of our coworkers, and seek to promote the faith within ourselves.

The most noticeable feature in the comparative exhibit in Table I. is the contrast 
between the steady increase in membership and the absence of any marked deviation in the number of members who have contributed to the material of the association, excepting at the eighth annual meeting. This is all the more striking in view of the fact that the association receives communications 'by title,' and these are relatively few in number. The average attendance at the annual meetings is almost thirty-five. The average number annually elected to membership is almost twelve. But the average number of contributing members is only about twenty, a number which remains well-nigh constant.

A more- forceful, and thus a more interesting, way of showing the aggregate individual distribution of the industry that has found place among us annually is given in the following summary, which includes two or three instances of joint authorship. Eighty-nine members have been the total contributors, of whom thirty-four have presented one unit, as paper, report, etc., each; twenty-three have presented two units each; ten have presented three each; eight have presented four each; five have presented five each; three have presented six each; two have presented seven each; one member has presented fourteen, one seventeen, one nineteen and one twenty-three units.

The remaining fifty-nine members have been inactive, silently paying their annual dues. It is, indeed, a serious question whether the association can hasten its realizations by carrying forty per cent. empty baggage, or whether this phase of the situation should not be radically changed. Almost twenty-six per cent. of the total contributions offered has been the work of four members, who are laboratory men. It will not be overlooked that they have simply stood as sponsors mostly for the work done by the student body of researchers working under their direction. No one would, of course, give an unequivocal sanction to much speaking as a psychological test. But such a summary shows the lines of inevitable fruitfulness.

Again the inevitable query bears in upon us: What of the value of the material which has been thus variously presented from time to time? But we must continue to set it aside. If one attempts to judge its worth, and the advance of science through its worth, he runs into the danger of maintaining that the field over which we have trod remains sub judice. And, moreover, it might reveal an immodest immaturity, to say the least, should one attempt to anticipate our psychological posterity in its function of judging of the offerings which have been brought hither year by year.

There is one function which the association can properly undertake more seriously, which would tend to secure a steady advance in the value of the newer material psychological researches may bring forth. At present the indefinite and uncertain method of 'natural selection' or mere survival of interest in individual cases is the only mode of checking off results. An improvement over this method would be a planful arrangement whereby the association could see to it that the annual output of new conclusions and formulæ is intelligently and critically evaluated. This would effect a great saving of individual labor on the part of each psychologist.

Edward Franklin Buchner.

University of Alabama.

(To be continued.)

\section{PROFESSOR ALEXANDER GRAHAM BELL ON KITE-CONSTRUCTION.}

IT is fortunate for those interested in aeronautics and the exploration of the air 